\title{
How to build a better mouse
}

The Collaborative Cross project will boost diversity and help the hunt for disease genes.

\section{BY EWEN CALLAWAY}

I t has taken nearly a century, but mouse geneticists are finally finishing the work started by Abbie Lathrop. The former schoolteacher from Massachusetts bred many of what became the first laboratory strains of mice in the early 1900s, yet her animals carried only a sliver of the genetic diversity found in wild mice. The hundreds of strains of laboratory mice used today still have a pretty narrow range of traits, which hampers the search for diseasecausing genes.

Now, the Collaborative Cross, an ambitious project to create hundreds more mouse varieties representing a wider range of genetic diversity, is beginning to deliver its first animals. The new mouse strains have some very visible differences from one another - from variations in fur colour to tail length - and are already yielding clues to genes that help fend off fungal infection, which might not have been easily uncovered with standard lab strains ${ }^{1-3}$.

Many classic laboratory strains, such as C57BL/6 - the first mouse to have its genome sequenced - owe much of their genetic make-up to the same handful of ancestors. These strains differ from each other in certain ways, such as the ability to battle infection, but not nearly as much as do wild mice. Huge chunks of the genomes of these strains are essentially identical, making it difficult and time-consuming to link particular traits to single genes within these genetic blind spots.

"Everyone realized there's a truckload of variation that we aren't seeing at all," says Richard Mott, a statistical geneticist at the University of Oxford, UK, who is involved in the project.

Begun at the US Department of Energy's Oak Ridge National Laboratory in 2005, the Collaborative Cross project selected five classic inbred strains, along with three more recently developed wild-derived strains, and began to breed them and their offspring together to reshuffle their genes.

To create genetically uniform inbred strains, brothers and sisters were mated for many generations. So far, the Collaborative Cross has established about 30 fully inbred mouse lines,

says Gary Churchill, a mouse geneticist at the Jackson Laboratory in Bar Harbor, Maine, one of the researchers who conceived the project.

The mice are already beginning to pay dividends. Fuad Iraqi, a geneticist participating in the Collaborative Cross at Tel Aviv University, Israel, tested 66 nearly inbred strains for their susceptibility to infection by

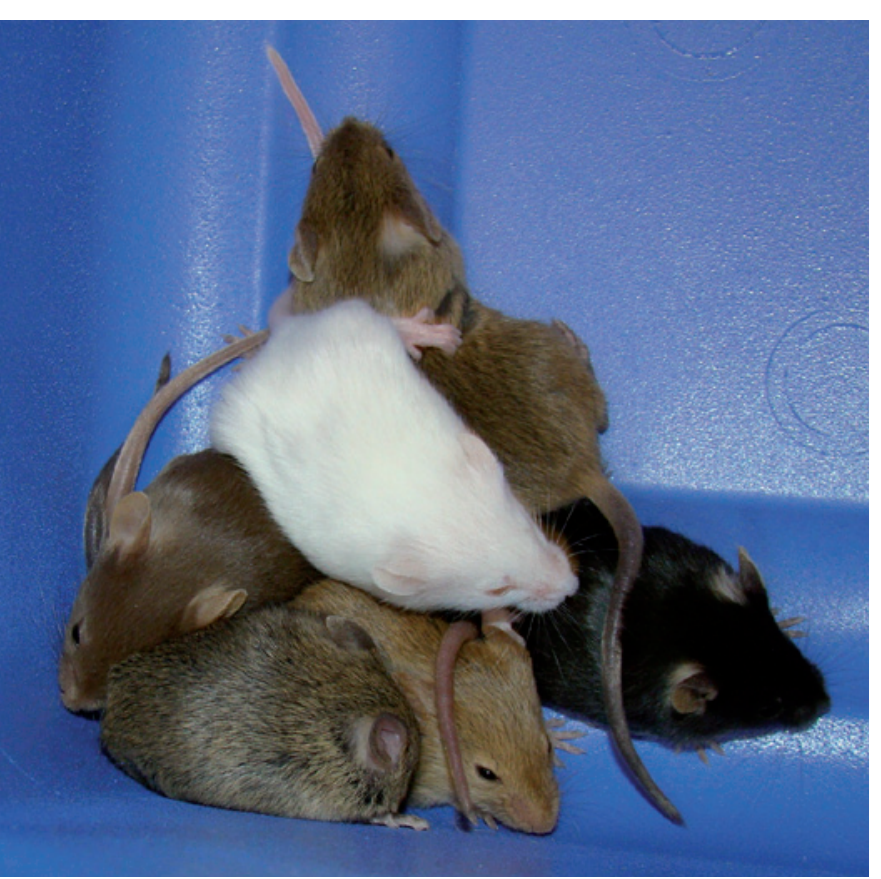

Rudolph Balling, director of the Luxembourg Centre for Systems Biomedicine, believes that the Collaborative Cross mice will become even more valuable when researchers start pooling their knowledge so that they can draw connections between seemingly distinct traits that have common genetic origins. "There has to be integrated database. That's the key to the whole thing," Balling says.

Steve Brown, director of the Mammalian Genetics Unit at MRC Harwell, UK, says the Collaborative Cross will mesh well with another project - the International Knockout Mouse Consortium - to create thousands of knockout strains collectively lacking nearly every mouse gene (see Nature 474, 262-263; 2011). For instance, a gene knockout that affects a mouse's sensitivity to diabetes could be linked to other traits of the syndrome, such as altered glucose metabolism, through the Collaborative Cross.

No database exists to help scientists forge such connections at present, and there is little capacity to shuttle hundreds of different mouse strains all over the world. So those involved with the Collaborative Cross are working with the University of North Carolina in Chapel Hill to

Aspergillus fumigatus, a soil fungus that causes a respiratory disease in humans.

Depending on the strain, the mice survived between 4 and 28 days after infection. On the basis of genotype information for the new strains and the genome sequences of the eight founder strains, Iraqi's team mapped these differences in survival time to just a handful of genomic regions, containing a small number of genes ${ }^{3}$. Future studies in 'knockout' mice lacking these genes should pin down exactly which ones are responsible for fungal resistance, Iraqi says.

Getting to this point with the Collaborative Cross mice took only a year, compared with the decade and a half Iraqi estimates it would have taken with the classic strains. "It is amazing," he says. His team is taking the same approach to map genes involved in defence against the bacterium Klebsiella pneumoniae and other traits.

"I don't think results are going to trickle out, they're going to be bursting," Churchill says. colonize the world's labs with the new mice. They plan to send out breeding pairs of the first strains by the end of this year, with up to 100 strains available by 2012 . "The idea is to make these available as broadly as possible," Churchill says.

1. Aylor, l. et al. Genome Res. http://dx.doi. org/10.1101/gr.111310.110 (2011).

2. Philip, V. et al. Genome Res. http://dx.doi. org/10.1101//gr.113886.110 (2011).

3. Durrant, C. et al. Genome Res. http://dx.doi. org/10.1101/gr.118786.110 (2011).

\section{CORRECTION}

The News story 'Paxil study under fire' (Nature 475, 153; 2011) gave the wrong affiliation for Charles Bowden. He is a clinical professor of psychiatry and pharmacology at the University of Texas Health Science Center, San Antonio. 